\title{
LOS OBJETIVOS DEL MERCOSUR \\ Y LA OPCIÓN DE FORO
}

\section{OS OBJETIVOS DO MERCOSUL E A OPÇÃO DE FORO}

Roque F. Silguero ${ }^{1}$

Resumen: La cláusula de opción de foro es utilizada en los sistemas de solución de controversias pertenecientes a áreas de preferencias arancelarias y a zonas de libre comercio, es decir, en esquemas que, dudosamente, pueden ser calificados como procesos de integración. Por el contrario, cuando se analizan procesos de integración con objetivos más comprometidos y de mayor alcance, como un mercado común o una unión económica, los sistemas de solución de controversias acordados en ellos introducen la figura de la jurisdicción exclusiva y excluyente.

En este sentido, el MERCOSUR, que tiene como objetivo la constitución de un el mercado común requiere, necesariamente, de un conjunto de soluciones de carácter técnico-jurídico que consolide los esfuerzos llevados a cabo en el campo económico y comercial. Bajo esta perspectiva, la opción de foro termina afectando la credibilidad de las instituciones del MERCOSUR, en un aspecto tan sensible como la solución de controversias.

Resumo: A opção de foro é utilizada nos sistemas de solução de controvérsias vinculadas a áreas de preferências e zonas de livre comércio, é dizer, em esquemas que, raramente, podem ser qualificados como processos de integração. Ao contrário, quando se analisam processos de integração com objetivos mais comprometidos e de maior alcance, como um mercado comum o uma união econômica, os sistemas de solução de controvérsias acordados em eles introduzem a figura da jurisdição exclusiva e excludente.

Assim, o MERCOSUL, que tem o objetivo de constituir um mercado comum requer, necessariamente, um conjunto de soluções de caráter técnico-jurídico que consolide os esforços levados a cabo no campo econômico e comercial. Sob essa perspectiva, a opção de foro acaba afetando a credibilidade das instituições do MERCOSUL em aspecto tão sensível como a solução de controvérsias.

Palabras clave: Opción de Foro, Solución Jurídico-institucional, Solución de Controversias, Proceso de Integración, Mercado Común

1 Abogado, Magister en Procesos de Integración Regional, Profesor titular de MERCOSUR I, Universidad Nacional de Formosa, Vicerrector de la Universidad Nacional de Formosa, Argentina. 
Palavras-chave: Opção de Foro, Solução Jurídico-institucional, Solução de controvérsias, Processo de Integração, Mercado Comum

\section{Introducción}

El objetivo de esta ponencia es bastante acotado, pues se dirige a efectuar una breve descripción de la denominada cláusula de opción de foro, incluida en el Protocolo de Olivos para la Solución de Controversias en el MERCOSUR (PO) $)^{2}$.

En esta faena, se intentará vincular el contenido y el alcance del consignado dispositivo, con la consecución de las metas particulares del PO y de los objetivos más generales del MERCOSUR, según los designios del Tratado de Asunción (TA) e instrumentos y normas complementarios.

No se reclama originalidad en esta propuesta, en gran medida, debido a que esta cuestión ha sido profusamente trabajada por especialistas del Derecho de la integración; más bien, se pretende tomar a la opción de foro como una excusa que dispare un análisis de las debilidades - y hasta retrocesos institucionales- padecidos por el MERCOSUR, y que le impiden, en definitiva, avanzar con decisión en el cumplimiento de su objetivo final, esto es, constituirse en un mercado común.

Entendemos que estos temas, como tantos otros que atañen a la integración regional, deben ser recordados y retomados de manera permanente en toda ocasión en la que se trate cuestiones jurídico-institucionales del MERCOSUR. Emulando -en cierta medida, y quizás con exageración- la tozudez de Catón "El Censor", cuando repetía incansablemente en sus intervenciones ante el senado romano, resultare o no pertinente, la fórmula que advertía a Roma respecto de sus enemigos: "Carthago delenda est", y adaptando lo que se deba adaptar, nosotros decimos que la opción de foro debe ser eliminada del PO, aun cuando dicho pedido se haya reiterado ya demasiadas veces.

Algunas razones que tratan de dar cuenta de este pedido serán esgrimidas a continuación.

2 Texto consultado en: Secretaría del MERCOSUR, Solución de controversias en el MERCOSUR, Recopilación Normativa, Montevideo, 02 de enero de 2012, pág. 9 y ss. 


\section{La cláusula de opción de foro en el PO}

La opción de foro, señalada en su momento como una de las innovaciones introducidas por el PO respecto de su antecesor, el Protocolo de Brasilia ${ }^{3}$, se halla normada en el Art.1.2, donde se lee:

"Las controversias comprendidas en el ámbito de aplicación del presente Protocolo que puedan también ser sometidas al sistema de solución de controversias de la Organización Mundial del Comercio o de otros esquemas preferenciales de comercio de que sean parte individualmente los Estados Partes del Mercosur, podrán someterse a uno u otro foro a elección de la parte demandante. Sin perjuicio de ello, las partes en la controversia podrán, de común acuerdo, convenir el foro. Una vez iniciado un procedimiento de solución de controversias de acuerdo al párrafo anterior, ninguna de las partes podrá recurrir a los mecanismos establecidos en los otros foros respecto del mismo objeto, definido en los términos del artículo 14 de este Protocolo. No obstante, en el marco de lo establecido en este numeral, el Consejo del Mercado Común reglamentará los aspectos relativos a la opción de foro".

La primera parte de la norma transcripta, establece el derecho que le asiste a la parte demandante, como así también al demandante y al demandado de manera conjunta y acordada, a elegir el foro, en una suerte de jurisdicción alternativa ${ }^{4}$, donde se irán a dirimir las controversia señaladas en el numeral 1 del mismo artículo.

Una vez efectuada dicha elección, surge inmediatamente la limitación, pues elegido el foro -el propio PO u otro en el que los Estados Partes en conflicto sean partes individualmente- con ello se produce la exclusión ${ }^{5}$ de todo otro foro o la prohibición ${ }^{6}$, si se prefiere, de recurrir

3 El PO incorporó el Tribunal Permanente de Revisión y las opiniones consultivas, entre otras innovaciones.

4 Martínez Puñal, A., "El Protocolo de Olivos para la solución de controversias en el Mercosur: una reforma en clave continuista", en Anuario de Derecho Europeo, Universidad de Sevilla, $\mathrm{N}^{\circ} 3,2003$, pág. 181.

$5 \quad$ Según la doctrina regional, "El texto acordado otorga al demandante la libertad de optar por el sistema que considere que cubre mejor sus intereses, evaluando a la vez las circunstancias de plazos o de costo que puedan incidir en su elección. Sin embargo, en todos los casos la opción implica la exclusión del otro foro...". Boldorini, M.C., "Protocolo de Olivos, Innovaciones en el Sistema de Solução de Controversias del Mercosur", en Solução de Controvérsias no Mercosul, Câmara dos Deputados do Brasil, Brasília, 2008, pág. 146 y 147. Ver, asimismo, Pizzolo, C., Derecho e integración regional, Ediar, Bs.As., 2010, pág. 1054 y 1055.

$6 \mathrm{Al}$ decir de B. Feder, "Lo que establece entonces el PO es más que una opción. Es una prohibición. La opción existía de modo no expreso en Brasilia. La innovación se ciñe, en realidad, a la prohibición; prohibición que implica la preclusión de la posibilidad de acceder a cierto foro 
a otros mecanismos de solución de controversias relacionados con el mismo objeto de disputa.

Completa esta disposición las normas establecidas en el Reglamento del $\mathrm{PO}^{7}$. El Art. 1 del mismo, respecto de la opción de foro, dice:

"1. Si un Estado Parte decidiera someter una controversia a un sistema de solución de controversias distinto al establecido en el Protocolo de Olivos, deberá informar al otro Estado Parte el foro elegido. Si en el plazo de quince (15) días, contados a partir de dicha notificación, las partes no acordaran someter la controversia a otro foro, la parte demandante podrá ejercer su opción, comunicando esa decisión a la parte demandada y al Grupo Mercado Común (en adelante GMC).

2. La opción de foro debe plantearse antes del inicio del procedimiento previsto en los artículos 4 y 41 del Protocolo de Olivos.

3. Se entiende que un Estado Parte optó por el sistema de solución de controversias del Protocolo de Olivos al solicitar el inicio de los procedimientos previstos en sus artículos 4 y 41 .

4. A los efectos de este artículo, se considerará iniciado un procedimiento bajo el sistema de solución de diferencias de la Organización Mundial del Comercio, cuando la parte demandante solicite la conformación de un Grupo Especial en los términos del artículo 6 del Entendimiento Relativo a las Normas y Procedimientos por el que se Rige la Solución de Diferencias.

5. El Consejo del Mercado Común (en adelante CMC) reglamentará oportunamente la aplicación del presente artículo con relación a los sistemas de solución de controversias de otros esquemas preferenciales de comercio".

¿Qué justificación surge en lo inmediato en cuanto a la inclusión de este dispositivo en el PO? Como se sabe, los países del MERCOSUR son todos miembros de la Organización Mundial del Comercio (OMC) y además participan en una compleja trama de acuerdos comerciales,

cuando se iniciaron las actuaciones en el otro. O sea, el comienzo de los procedimientos en el marco del régimen regional implicará que no puede accederse luego al multilateral y al revés". Feder, B., "El Protocolo de Olivos para la solución de controversias del MERCOSUR: algunos aspectos particulares (técnico jurídicos, orgánico institucionales, procesales)", en Solução de Controvérsias no Mercosul, op.cit., pág. 25.

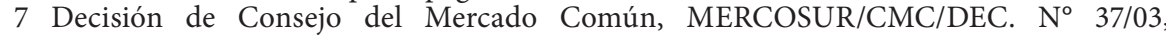
"Reglamento del Protocolo de Olivos para la solución de Controversias en el MERCOSUR", en Secretaría del MERCOSUR, Solución de controversias..., cit., pág. 27. 
en cuyas estructuras se observan también mecanismos de solución de diferencias. Entonces, la cláusula se justifica, al parecer, por la necesidad de neutralizar el escándalo jurídico que supondría una controversia presentada, de manera simultánea o sucesiva, en dos o más foros a los que tuvieran acceso los Estados Partes. Se trata de evitar la duplicidad de procedimientos y las resoluciones contradictorias, según se ha sostenido ${ }^{8}$. Si ello sucederla se vulnerarían principios jurídicos elementales, comenzando con el "non bis in ídem", el que indica que un asunto no puede ser juzgado dos veces por idénticas razones, afectándose, consecuentemente, otros principio conexos: "cosa juzgada", seguridad jurídi$\mathrm{ca}^{9}$ y litispendencia ${ }^{10}$.

Pero más allá de las argumentaciones jurídicas que explican este instituto dentro del $\mathrm{PO}$, lo cierto es que su regulación está más vinculada a razones de hecho. El "escándalo" de decisiones contradictorias, al que se aludiera más arriba, efectivamente sucedió en el marco del régimen de controversias establecido en el Protocolo de Brasilia. Como se sabe, en el recordado caso "pollos eviscerados"11, el Tribunal Arbitral Ad Hoc de MERCOSUR emitió un laudo favorable a posición Argentina, ante lo cual, Brasil, desoyendo el mismo, sometió nuevamente la controversia a examen, esta vez ante el sistema de la OMC, obteniendo allí sí, satisfacción a sus requerimientos iniciales ${ }^{12}$. Ante esta situación,

8 Pimentel, L.O.; Dreyzin de Klor, A."O sistema de solução de controvérsias do Mercosul”, en Dreyzin de Klor, A.;Pimentel, L.O.; Kegel, P.L.; Barral, W., Solução de controvérsias - OMC, União Europeia e Mercosul. Fundação Konrad Adenauer, Rio de Janeiro, 2004, pág. 174.

9 Ver, por ejemplo, García del Río, M., "La solución de controversias en los acuerdos del MERCOSUR con otros países o esquemas de integración", en Solução de Controvérsias no Mercosul, op.cit., pág. 178. Sobre la seguridad jurídica, se tiene que esta se hace presente cuando "...la división de poderes no es respetada; cuando los jueces invaden la esfera de actuación propia de los funcionarios administrativos; los funcionarios del Estado ignoran los precedentes judiciales; los funcionarios del Estado permanecen quietos cuando las reglas del Derecho vigente exige acción; los miembros de la comunidad violan los acuerdos contractuales o infringen reglas legales y las autoridades jurídicas competentes se abstienen de imponer sanciones en esas circunstancias; se atribuye efecto retroactivo a las regulaciones legislativas y administrativas; se aplican nuevas reglas a situaciones ya definidas y consolidadas en el pasado; se cambian o alteran las normas impositivas, etcétera". Grajales, A.A., Seguridad jurídica y Mercosur, Editorial Utopías, Ushuaia, 2011, pág. 171.

10 Pizzolo, C., op.cit., pág. 1055.

11 Laudo IV, "Laudo del Tribunal Arbitral Ad Hoc del Mercosur constituido para decidir sobre controversia entre la República Federativa de Brasil y la República Argentina sobre Aplicación de medidas antidumping contra la exportación de pollos enteros, provenientes de Brasil, (res. 574/2000) del Ministerio de Economía de la República Argentina"', del 21/05/2001. En el numeral 2 de esta decisión, el tribunal dispone: "No hacer lugar al petitorio de la parte Reclamante que solicita del Tribunal que declare el incumplimiento por la Parte Reclamada de las normas del Marco Normativo que cita y que ordene la revocación de la Resolución impugnada", pág. 45 .

12 En las recomendaciones formuladas por Grupo Especial que se ocupó del asunto "Argentina - Derechos antidumping definitivos sobre los pollos procedentes del Brasil", se lee: "Hemos determinado que la Argentina ha actuado de manera incompatible con las obligaciones que le incumben en virtud del Acuerdo Antidumping al imponer derechos antidumping sobre las importaciones de pollos eviscerados procedentes del Brasil. Hemos constatado que esas 
fue la propia República Argentina, en el marco de las negociaciones en torno a la reforma del régimen de solución de controversias, quién presionó por la inclusión de la opción de foro en lo que posteriormente sería el $\mathrm{PO}^{13}$.Dicha inclusión no estuvo exenta de resistencias ${ }^{14}$, lo que obligó a que se incluyera en el texto la facultad de reglamentación de la opción de foro en cabeza del Consejo del Mercado Común.

\section{Algunos antecedentes}

La opción de foro está presente en un número importante de acuerdos internacionales, alguno de los cuales, al parecer, fueron tenidos en cuenta como base para el PO. Se revisará, a continuación, algunos precedentes generales, para citar también aquellos que de manera más específica se ajustan a este estudio.

\section{1) La opción de foro en el Derecho internacional de los Dere chos Humanos}

El carácter excluyente de la opción de foro también se manifiesta en el campo del Derecho internacional de los Derecho Humanos. Concretamente, la Convención Interamericana de Derecho Humanos establece una serie de requisitos de admisibilidad, entre los que se menciona la necesidad de inexistencia de dichas denuncias o quejas pendientes de tramitación por ante otros foros. El art. 46.1, letra c) de la Convención reza: "Para que una petición o comunicación...sea admitida por la Comisión, se requerirá: Que la materia de la petición comunicación no esté pendiente de otro procedimiento de arreglo internacional..." ${ }^{15}$. Para

infracciones tienen un carácter fundamental y un alcance general....En vista del carácter y el alcance de las infracciones constatadas en el presente asunto, no podemos concebir cómo podría la Argentina aplicar correctamente nuestra recomendación sin revocar la medida antidumping en cuestión en la presente diferencia. Por consiguiente, sugerimos que la Argentina derogue la Resolución No 574/2000 por la que se imponen medidas antidumping definitivas sobre los pollos eviscerados procedentes del Brasil". OMC, Grupo Especial, "Argentina-Derechos antidumping definitivos sobre los pollos procedentes del Brasil”, Diferencia DS355, WT/DS241/R, 22 de abril de 2003, pág. 120.

13 Para M.C.Boldorini, a la sazón coordinadora por la Argentina en el Grupo de Alto Nivel para la modificación del régimen de controversias del MERCOSUR, señala que "Argentina consideró esencial incluir en el instrumento una disposición sobre opción-exclusión de foro, debido a que todos los Estados Partes del Mercosur, al ser miembros de la Organización Mundial de Comercio (OMC), tienen abierta la posibilidad de recurrir a ese organismo internacional". Boldorini, M.C., op.cit., pág. 145. Según se desprende de publicaciones oficiales, además de la opción de foro, la Argentina se mostró muy interesada en la inclusión de un sistema de revisión de los laudos arbitrales emitidos por los Tribunales Ad Hoc realizada por un Tribunal de Revisión que tuviera carácter permanente, además de la regulación de la etapa "post-laudo", es decir el cumplimiento del laudo y los efectos de su eventual incumplimiento (medidas compensatorias). Ver: Secretaria de Comercio Exterior, "Mecanismos de Solución de controversias en el Mercosur", en: www.comercio.gob.ar; fecha de captura: 27/10/2012.

14 Feder, B., op.cit., pág. 26.

15 Tratados y Documentos Internacionales, Convención Americana sobre Derecho 
C.Pizzolo, esta regla tiene por objetivo “...evitar la duplicación de procedimientos y se justifica en el principio de economía procesal y en la necesidad de evitar pronunciamientos contradictorios o conflictos de competencia"16.

Por su parte, el Protocolo Facultativo del Pacto Internacional de Derechos Civiles y Políticos, dispone en el mismo sentido, en su art. 5.2, que "El Comité no examinará ninguna comunicación de un individuo a menos que se haya cerciorado de que: a) El mismo asunto no ha sido sometido ya a otro procedimiento de examen o arreglo internacionales..."17.

Disposición análoga se verifica contenida en el "Convenio para la Protección de los Derechos Humanos y de las Libertades Fundamentales", en el marco del Sistema Europeo de Derechos Humanos ${ }^{18}$, vigente desde 1950, dispone en su art. 35.2, que "El Tribunal no admitirá ninguna demanda...34 cuando... b) sea esencialmente la misma que una demanda examinada anteriormente por el Tribunal o ya sometida a otra instancia internacional de investigación o de acuerdo, y no contenga hechos nuevos" 19 .

En todos estos casos, la justificación resulta la misma, impedir la duplicidad de procedimientos, apuntando a evitar los pronunciamientos encontrados elaborados en distintos foros ${ }^{20}$.

\section{2) Acuerdos comerciales y procesos de integración regional}

\section{$(\mathrm{CAN})^{21}$}

\subsubsection{Tratado de Libre Comercio de América del Norte (TL-}

El Tratado que diera nacimiento al TLCAN, en su art. 2005 recepta la opción de foro, si bien reducida en cuanto a las posibilidades de

Humanos, Zavalía, Bs.As., pág. 375.

16 Pizzolo, C., op.cit., pág. 1055. Ver, asimismo, Flax, G.A., "Procedimiento para conocer de violaciones aisladas de Derecho Humanos", en Gordillo, A., Derechos Humanos, Fundación de Derecho Administrativo, Bs.As., 1999, pág. XIII-3.

17 Texto consultado en: Oficina del Alto Comisionado de Naciones Unidas para los Derecho Humanos, www2.ohchr.org; fecha de captura: 27/10/2012.

18 Ver, por ejemplo: Maskin, H., El sistema europeo de Derechos humanos, Eudeba, Bs.As., 1987, pág. 16.

19 Tribunal Europeo de Derechos Humanos, Convenio Europeo de Derechos Humanos, Secretaría del Tribunal Europeo de Derechos Humanos, Strasbourg, 2010, pág. 24.

20 Travieso, J.A., Derechos Humanos y Derecho internacional, Heliasta, Bs.As., 1996, pág. 418.

21 También conocido por su denominación en inglés), North American Free Trade Agreement (NAFTA), y francés, Accord de libre-échange nord-américain (ALÉNA), fue suscrito por EE.UU., Canadá y México el 17 de diciembre de 1992 y entró en vigencia a partir del $1^{\circ}$ de enero de 1994, cuando se cumplió con el procedimiento de ratificación. Texto del tratado consultado en: www.nafta-sec-alena.org; fecha de captura: 27/10/2012. 
elección, puesto que sólo admite su propio régimen o el establecido por la OMC. El numeral 1 de dicha norma dice:

"Excepto lo dispuesto en los párrafos 2, 3 y 4, las controversias que surjan con relación a lo dispuesto en el presente Tratado y en el Acuerdo General sobre Aranceles Aduaneros y Comercio, en los convenios negociados de conformidad con el mismo, o en cualquier otro acuerdo sucesor (GATT), podrán resolverse en uno u otro foro, a elección de la Parte reclamante".

La opción de foro le corresponde, según el tratado, a la parte reclamante, pero, en última instancia, parece entreverse una suerte de prioridad a favor del dispositivo regional. En efecto, en el caso que la parte reclamada -que debe ser consultada en todos los casos- insista en preferir el foro local, la controversia será dirimida en ese ámbito. Esto es lo que se desprende del numeral 2 del mismo artículo señalado: "Antes de que una de las Partes inicie un procedimiento de solución de controversias contra otra Parte ante el GATT, esgrimiendo fundamentos sustancialmente equivalentes a los que pudiera invocar conforme a este Tratado, notificará a la tercera Parte su intención de hacerlo. Si respecto al asunto la tercera Parte desea recurrir a los procedimientos de solución de controversias de este Tratado, lo comunicará a la Parte notificadora lo antes posible y esas Partes consultarán con el fin de convenir en un foro único. Si las Partes consultantes no llegan a un acuerdo, la controversia normalmente se solucionará según los lineamientos de este Tratado"22.

\subsubsection{Asociación Latinoamericana de Integración (ALADI)}

La ALADI, pese a no contar con un régimen propio de solución de diferencias incluido en el Tratado de 1980 o en un instrumento de igual jerarquía ${ }^{23}$, ha sido un ámbito muy prolífico en cuanto a la regu-

22 Tal preferencia por el sistema de solución de controversias del TLCAN se observa también en los numerales 3 y 4, respecto de materias específicas como: agropecuarias, sanitarias, fitosanitarias, ambientales, salud, seguridad: "3. En las controversias a que hace referencia el párrafo 1, cuando la Parte demandada alegue que su acción está sujeta al Artículo 104, "Relación con tratados en materia ambiental y de conservación", y solicite por escrito que el asunto se examine en los términos de este Tratado, la Parte reclamante podrá sólo recurrir en lo sucesivo y respecto de ese asunto, a los procedimientos de solución de controversias de este Tratado. 4. En las controversias a que hace referencia el párrafo 1, que surjan respecto a la Sección B del Capítulo VII, "Sector agropecuario y medidas sanitarias y fitosanitarias", o en relación con el Capitulo IX, "Medidas relativas a normalización": (a) sobre una medida que una Parte adopte o mantenga para la protección de la vida o la salud humana, animal o vegetal, o del medio ambiente; y (b) que den lugar a cuestiones de hecho relacionadas con el medio ambiente, la salud, la seguridad o la conservación, incluyendo las cuestiones científicas directamente relacionadas, cuando la Parte demandada solicite por escrito que el asunto se examine conforme a este Tratado, la Parte reclamante sólo podrá recurrir en lo sucesivo, respecto de ese asunto, a los procedimientos de solución de controversias de este Tratado".

$23 \mathrm{El}$ art. 35 del Tratado de Montevideo de 1980, que diera nacimiento a este organismo, 
lación de los conflictos entre sus Estados Partes, incorporando normas sobre la materia en los acuerdos de alcance parcial (AAP) ${ }^{24}$. A su vez, un buen número de estos acuerdos contiene en sus disposiciones referencias a la opción de foro, tomando como foro alternativo, en todos los casos consultados, el sistema de la $\mathrm{OMC}^{25}$. Aún más, de la letra de estos acuerdos se puede inferir, sin dificultad alguna, que ellos han sido una fuente directa para los redactores del art. 2.1 del PO y su reglamentación ${ }^{26}$. Al sólo efecto ejemplificativo, citamos aquí el AAP.CE $\mathrm{N}^{\circ} 62^{27}$, entre el MERCOSUR y Cuba, en cuyo régimen de solución de contro-

contiene una disposición muy tenue respecto de la solución de controversias, limitándose a señalar que: "El Comité es el órgano permanente de la Asociación y tendrá las siguientes atribuciones y obligaciones: ...m) Proponer fórmulas para resolver las cuestiones planteadas por los países miembros, cuando fuera alegada la inobservancia de algunas de las normas o principios del presente Tratado". Tratado de Montevideo, Montevideo, agosto de 1980; texto consultado en: www.aladi.org; fecha de captura: 29/10/2012. Ver, por ejemplo: ALADI, "Necesidad $y$ conveniencia del desarrollo de un régimen general de alcance regional sobre medios para la solución de controversias en el ámbito de la ALADI", Secretaría general, LADI/Sec/Estudio 83, 6 de marzo de 1995.

24 El art. 7 del Tratado de Montevideo de 1980 dispone: "Los acuerdos de alcance parcial son aquéllos en cuya celebración no participa la totalidad de los países miembros, y propenderán a crear las condiciones necesarias para profundizar el proceso de integración regional mediante su progresiva multilateralización. Los derechos y obligaciones que se establezcan en los acuerdos de alcance parcial regirán exclusivamente para los países miembros que los suscriban o que a ellos adhieran". El art. 8, completa el anterior, agregando: "Los acuerdos de alcance parcial podrán ser comerciales, de complementación económica, agropecuarios, de promoción del comercio o adoptar otras modalidades de conformidad con el artículo 14 del presente Tratado".

25 En una investigación de carácter no exhaustivo, hemos advertido la existencia de cláusulas de opción de foro en 19 acuerdos de alcance parcial: AAP.CE N 36, ArgentinaMéxico, Decimotercer Protocolo Adicional, suscripto el 13/03/2001, art. 3; AAP.CE $\mathrm{N}^{\circ} 58$, MERCOSUR-Perú, Primer Protocolo Adicional, suscrito el 30/11/2005, art. 3; AAP.CE $\mathrm{N}^{\circ} 33$, Colombia-México-Venezuela, suscripto el 13/06/1994, art. 19-03; AAP.CE No 38, Chile-Perú, Tercer Protocolo Adicional, suscripto el 01/03/2009, art. 16.3; AAP.CE N 31, Bolivia-Uruguay, suscripto el 10/09/1994, art.19-03; AAP.CE N ${ }^{\circ}$ 65, Chile-Ecuador, suscripto el 25/10/2008, art. 14.3; AAP.CE $\mathrm{N}^{\circ}$ 41, Chile-México, suscripto el 17/04/1998, art.18-03; AAP.CE $\mathrm{N}^{\circ} 6$, Argentina-México, Decimotercer Protocolo Adicional, suscripto el 13/02/2011, art. 3.; AAP. $\mathrm{CE} \mathrm{N}^{\circ}$ 42, Segundo Protocolo Adicional, Anexo 6, art. 2; AAP.CE N ${ }^{\circ}$ 45, Argentina-Cuba, Primer Protocolo Adicional, suscripto el 08/08/2007, Anexo, art. 3; AAP.CE N ${ }^{\circ}$ 47, BoliviaCuba, Primer Protocolo Adicional, suscripto el 08/05/2000, Anexo V, art. 3; AAP.CE $N^{\circ} 49$, Colombia-Perú, Segundo Protocolo Adicional, suscripto el 01/02/2008, Anexo VI, art. 3; AAP.CE N ${ }^{\circ}$ 59, MERCOSUR-Comunidad Andina, Primer Protocolo Adicional, suscripto el 12/05/2005, art. 3; AAP.CE $N^{\circ}$ 60, Uruguay-México, suscripto el 15/11/2003, art. 18-01; AAP.CE $N^{\circ}$ 61, Colombia-Venezuela-México, suscripto el 07/12/2004, art. 4; AAP.CE $N^{\circ} 67$, México-Perú, suscripto el 06/04/2011, art. 15.3; AAP.CE Nº 5, México-Uruguay, Decimosexto Protocolo Adicional, suscripto el 29/12/1999, art. 2; AAP.CE $\mathrm{N}^{\circ}$ 35, MERCOSUR-Chile, Vigesimosegundo Protocolo Adicional, suscripto el 19/10/1999, Anexo, art. 2; AAP.CE N$^{\circ} 36$, MERCOSUR-Bolivia, Decimotercer Protocolo Adicional Rectificado, suscripto el 19/06/2001, Anexo, art. 1.

26 Esta apreciación es confirmada por una de las diplomática intervinientes en la concepción del PO, cuando manifiesta que “...Argentina formuló su propuesta, luego de haber analizado las disposiciones de varios acuerdos comerciales, entre ellos: el ACE 35 y el ACE 36, que disponen la opción de foro en controversias sobre dumping y subsidios; el G-3 (Colombia, México, Venezuela); los bilaterales México-Uruguay; Canadá-Chile; Centroamérica-Chile; México-Triángulo Norte (El Salvador, Guatemala, Honduras); y el Proyecto sobre Solución de Controversias de la ALADI de 1999". Boldorini, M.C., op.cit., pág. 146.

27 AAP.CE N ${ }^{\circ} 62$, MERCOSUR-Cuba, suscripto el 21/08/2006, Anexo VIII. 
versias, art. 2, se lee:

"No obstante lo dispuesto en el Artículo 1, las controversias que surjan en relación con lo dispuesto en este Acuerdo, en las materias reguladas por el Acuerdo de Marrakech por el que se establece la Organización Mundial del Comercio (en adelante “Acuerdo OMC") y en los convenios negociados de conformidad con el mismo, podrán resolverse en uno u otro foro, a elección de la parte reclamante.

Una vez que se haya iniciado un procedimiento de solución de controversias conforme al presente Anexo, o bien uno conforme al Acuerdo OMC, el foro seleccionado será excluyente del otro.

Para efectos de este artículo, se considerarán iniciados los procedimientos de solución de controversias conforme al Acuerdo OMC cuando la parte reclamante solicite la integración de un panel de Acuerdo con el Artículo 6 del Entendimiento Relativo a las Normas y Procedimientos por los que se rige la Solución de Diferencias que forma parte del Acuerdo OMC.

Asimismo, se considerarán iniciados los procedimientos de solución de controversias conforme al presente Acuerdo, una vez convocada la Comisión Administradora de conformidad con lo dispuesto en el Artículo 7”.

La posibilidad de elegir el foro donde se habrán de plantear las controversias, según autorizada doctrina, “...é a tendência que prevalece nos acordos econômicos regionais" ${ }^{28}$, $\mathrm{y}$, a juzgar por el número de AAP que lo incluyen en su articulado, la citada opinión parece incontrastable. Que sea la solución adecuada para un proceso como el MERCOSUR, ya es un asunto diferente, y que se analizará más adelante en este trabajo.

\subsubsection{Comunidad Andina (CAN)}

El sistema de solución de controversias de la CAN se encuentra en una fase muy desarrollada ${ }^{29}$, por lo que no sorprende que en el Tratado

28 Pimentel, L.O.; Dreyzin de Klor, A., op.cit., pág. 174.

29 Según se lo ha descripto, "Entre las características del TJCA podemos destacar: a) es un órgano independiente tanto de los Estados como de las instituciones comunitarias andinas; $b$ ) es de carácter supranacional porque sus integrantes son independientes de los Estados miembros los cuales han atribuido competencias jurisdiccionales al tribunal lo que permite al órgano comunitario tomar decisiones que vinculan a los Estados miembros, aún en caso de oposición de éstos, a la vez que dichas decisiones tienen efecto directo, inmediato y prevalecen sobre el derecho interno; c) su jurisdicción es obligatoria en las competencias juzgadas y dotadas de reconocimiento y ejecutividad de pleno derecho en el territorio de los Estados miembros, lo que permite que sus sentencias tengan efecto inmediato". Pizzolo, C., op.cit., pág. 981. 
de creación de su Tribunal de Justicia, se declare la jurisdicción exclusiva y excluyente de este órgano respecto de la aplicación del derecho de la comunidad ${ }^{30}$, eliminándose así toda posibilidad de elección de foro. $\mathrm{El}$ art. 42 del instrumento consignado, dice:

\begin{abstract}
"Los Países Miembros no someterán ninguna controversia que surja con motivo de la aplicación de las normas que conforman el ordenamiento jurídico de la Comunidad Andina a ningún tribunal, sistema de arbitraje o procedimiento alguno distinto de los contemplados en el presente Tratado".
\end{abstract}

Conteste con la norma, el Tribunal de Justicia de la CAN reafirmó la exclusividad de su jurisdicción, señalando que "...Tratado de Creación del Tribunal, [...] le da a este órgano comunitario la exclusividad en la solución de controversias que surjan con motivo de la aplicación de las normas que conforman el ordenamiento jurídico del Acuerdo de Cartagena... los Países Miembros del Acuerdo de Cartagena, en el caso de diferencias sobre propiedad industrial surgidas entre ellos deberán someterse a la jurisdicción exclusiva del Tribunal de Justicia del Acuerdo de Cartagena, según lo prescrito por el artículo 33 de su Tratado de Creación"31.

\title{
3.2.4. Comunidad del Caribe (CARICOM)
}

Tanto en el tratado original que diera nacimiento al CARICOM, ${ }^{32}$ como a su tratado revisado ${ }^{33}$, se introduce de manera expresa la imposibilidad de recurrir a otro foro en la solución de controversias de la región. En el art. 211 de este último se lee:

30 La doctrina andina destaca la jurisdicción exclusiva del Tribunal de Justicia de la CAN: "Esta jurisdicción, como la europea, es una jurisdicción obligatoria, exclusiva y accesible, exceptuando la función arbitral que es voluntaria y optativa. El TTAJ ha dispuesto que todas las controversias que se presenten con ocasión de la aplicación de las normas de integración andina, se resolverán obligatoriamente [...] y de manera exclusiva mediante procedimientos precontenciosos y contenciosos establecidos en él. No podrá, por tanto, ventilarse ningún litigio de estas materias en tribunales distintos del TAJ". Nouel, E., Nuevos temas del derecho internacional, Editorial CEC, Carácas, 2006, pág. 156.

31 Tribunal de Justicia de la Comunidad Andina, Proceso No. 1-IP-96, "Solicitud de Interpretación Prejudicial, de los artículos 1, 2, 4, 6 y 7 de la Decisión 344 y 2 y 3 de la Decisión 345 de la Comisión del Acuerdo de Cartagena, en relación con el artículo $1^{\circ}$, numeral $3^{\circ}$ del Convenio de París para la protección de la Propiedad Industrial. Presentada por la Corte Constitucional de la República de Colombia", Quito, Diciembre 9 de 1996, pág. 9 y 11.

32 En el Anexo al Tratado original de la CARICOM, se observaba una norma que prohibía a los Estados miembros someter sus controversias a foros ajenos a la comunidad; el art. 12.9 de dicho anexo señalaba: "Member States undertake to employ the procedures set out in this Article for the settlement of any dispute specified in paragraph1 of Article11 and to refrain from any other method of disputes settlement". "Treaty Establishing the Caribbean Community", Chaguaramas, 4th July 1973, consultado en www.caricom.org; fecha de captura: 10/10/2012.

33 "Revised treaty of Chaguaramas establishing the Caribbean Community including the Caricom Single Market and Economy", Suscripto el 05/07/2001, consultado en: www.caricom. org; fecha de captura: 12/10/2012. 
"Subject to this Treaty, the Court shall have compulsory and exclusive jurisdiction to hear and determine disputes concerning the interpretation and application of the Treaty, including: (a) disputes between the Member States parties to the Agreement; (b) disputes between the Member States parties to the Agreement and the Community; (c) referrals from national courts of the Member States parties to the Agreement; (d) applications by persons in accordance with Article 222, concerning the interpretation and application of this Treaty" ${ }^{\prime 4}$.

\subsubsection{Organización de Estados centroamericanos (ODECA)}

La ODECA es un organismo regional creada en 1951. Integrada por Costa Rica, Guatemala, Honduras, Nicaragua y El Salvador, su objetivo es promover la cooperación e integración. En 1991 la ODECA crea el Sistema de la Integración Centroamericana (SICA) ${ }^{35}$. La solución de controversias del SICA está hoy en manos de la Corte Centroamericana de Justicia, creada a su vez por art. 12 del Protocolo de Tegucigalpa ${ }^{36}$. Este tratado, en su art. 35, en su último párrafo, disponía que "Toda controversia sobre la aplicación o interpretación de las disposiciones contenidas en el presente Protocolo y demás instrumentos a que se refiere el párrafo anterior, deberá someterse a la Corte Centroamericana de Justicia". Se establecía así una jurisdicción exclusiva y excluyente, conforme se ha repasado en los anteriores aparatados.

Sin embargo, este artículo sufrirá una modificación sustancial, a partir de una enmienda introducida al protocolo ${ }^{37}$, y que permite solucionar las controversias en otros foros pactados por los Estados miembros. En el art. 1 de esta, dice:

"Se modifica el artículo 35 el cual queda como sigue:

34 "Sin perjuicio de lo dispuesto en el presente Tratado, el Tribunal tendrá competencia obligatoria y exclusiva para oír y decidir las diferencias relativas a la interpretación y aplicación del Tratado, como por ejemplo: a) las diferencias entre los Estados Miembros que son parte en el Acuerdo; b) las diferencias entre los Estados Miembros de partes en el Acuerdo y la Comunidad; c) las referencias provenientes de los tribunales nacionales de los Estados Miembros que son parte en el Acuerdo; d) las solicitudes de personas físicas de conformidad con lo dispuesto en el artículo 222, relativas a la interpretación y aplicación del presente Tratado". (Esta traducción, y las que siguen, pertenecen al autor de esta ponencia).

35 "Protocolo de Tegucigalpa a la Carta de la Organización de Estados Centroamericanos (ODECA)", suscripta en Tegucigalpa, el 13/12/1991. Texto consultado en: www.sica.int; fecha de captura 12/10/2012.

36 Sobre la evolución del sistema jurisdiccional del SICA, ver: PIzzolo, C., op.cit., pág. 1015 y ss.

37 "Enmienda al Protocolo de Tegucigalpa a la Carta de la Organización de Estados Centroamericanos (ODECA)", suscripta en Managua, el 27/02/2002; texto consultado en www. sica.int; fecha de captura 12/10/2012. 
Artículo 35. Este Protocolo y sus instrumentos complementarios y derivados prevalecerán sobre cualquier Convenio, Acuerdo o Protocolo suscrito entre los Estados Miembros, bilateral o multilateralmente, sobre las materias relacionadas con la integración centroamericana. No obstante, quedan vigentes entre dichos Estados las disposiciones de aquellos Convenios, Acuerdos o Tratados, siempre que las mismas no se opongan al presente instrumento $\mathrm{u}$ obstaculicen el logro de sus propósitos y objetivos.

Salvo lo dispuesto en el párrafo siguiente, las controversias sobre la aplicación o interpretación de las disposiciones contenidas en el presente Protocolo y demás instrumentos a que se refiere el párrafo anterior, deberán someterse a la Corte Centroamericana de Justicia”.

Las razones de esta enmienda son expresadas en los considerandos de la misma, donde se sostiene, por ejemplo, "Que es necesario extender la posibilidad de conocimiento de las controversias surgidas en el ámbito comercial del Mercado Común Centroamericano: a los métodos alternos de solución de controversias, para contar con mecanismos modernos, ágiles, efectivos, vinculantes y con niveles de calidad superiores, o al menos, iguales a los alcanzados en los tratados comerciales de tercera generación suscritos por los países centroamericanos con terceros Estados".

\subsubsection{Unión Europea: jurisdicción exclusiva}

El actual art. 344 del Tratado de Funcionamiento de la Unión Europea (TFUE) (antiguo art. 292 del Tratado de las Comunidades Europeas (TCE), señala con claridad:

"Los Estados miembros se comprometen a no someter las controversias relativas a la interpretación o aplicación de los Tratados a un procedimiento de solución distinto de los previstos en los mismos" 38 .

Toda opción por otra jurisdicción que no sea la comunitaria queda absolutamente vedada en este esquema de integración. Se trata de una suerte de "monopolio jurisdiccional" 39 del Tribunal de Justicia respecto de los litigios relativos a la aplicación e interpretación del Derecho comunitario.

38 Unión Europea, "Versión Consolidada del Tratado de Funcionamiento de la Unión Europea", Diario Oficial de la Unión Europea, C 83, del 30/03/2010. Idéntico texto se observa en el art. 193 del tratado de la Comunidad Europea de la Energía Atómica.

39 Conclusiones del Abogado General Sr. M. Poiares Maduro, presentadas el 18 de enero de 2006, “Comisión/ Irlanda”, Asunto C-459/03, pág. I-4642. 
El Tribunal de Justicia de las Comunidades Europeas (TJCE) tuvo oportunidad de interpretar el texto citado por primera vez en el asunto "Comisión de las Comunidades Europeas contra Irlanda", del año $2006^{40}$. En dicho asunto, la Comisión sostuvo que Irlanda había vulnerado el art. 292, además del art. 10 y el art. 192, todos del TCE, al someter una controversia con el Reino Unido a un tribunal arbitral constituido conforme a la Convención de Naciones Unidas sobre el Derecho del Mar. El TJCE se expidió a favor de la posición sostenida por la Comisión, argumentando que "El Tribunal de Justicia ya ha recordado que un acuerdo internacional no puede menoscabar el orden de las competencias fijado por los Tratados y, por lo tanto, la autonomía del sistema jurídico comunitario cuyo respeto garantiza el Tribunal de Justicia en virtud del artículo 220 CE. Confirma esta competencia exclusiva del Tribunal de Justicia el artículo 292 CE, según el cual los Estados miembros se comprometen a no someter las controversias relativas a la interpretación o aplicación del Tratado CE a un procedimiento de solución distinto de los previstos en él"41; agregando que "...la obligación de los Estados miembros, establecida en el artículo $292 \mathrm{CE}$, de recurrir al sistema jurisdiccional comunitario y de respetar la competencia exclusiva del Tribunal de Justicia que constituye su rasgo fundamental debe interpretarse como una manifestación específica de su deber más general de lealtad que resulta del artículo $10 \mathrm{CE}^{342}$.

En cuanto a los fundamentos de esta competencia exclusiva y excluyente, el Abogado General de las Comunidades decía "La competencia exclusiva del Tribunal de Justicia sobre los litigios entre Estados miembros relativos al Derecho comunitario es una forma de preservar la autonomía del ordenamiento jurídico comunitario. Sirve para garantizar que los Estados miembros no contraigan obligaciones legales de Derecho internacional público que puedan entrar en conflicto con sus obligaciones de Derecho comunitario. Fundamentalmente, el artículo 292 CE y el artículo 193 EA expresan el deber de lealtad para con el sistema judicial establecido por los Tratados comunitarios. Los Estados miembros han acordado resolver sus diferencias por las vías previstas en los Tratados; deben abstenerse de someter sus controversias relacionadas con dichos Tratados a otros sistemas de solución de conflictos" ${ }^{43}$.

\section{3) Conclusiones provisorias}

De este análisis sumario, surgen algunas conclusiones de mucho interés. Dejando fuera los casos que se refieren al Derecho internacional

40 TJCE, “Comisión/Irlanda”, Sentencia del Tribunal de Justicia (Gran Sala) de 30 de mayo de 2006, en el asunto C-459/03.

41 Ídem, pág. I- 4708.

42 Ídem, pág. I-4717.

43 Conclusiones del Abogado General Sr. M. Poiares Maduro, cit., pág. I-4642. 
de los Derechos Humanos -vinculados más al principio de litispendencia que a la opción de foro y referidos a una materia específica, que trasciende, por otra parte, a los procesos de integración o a los simples acuerdos comerciales-, se puede advertir en los demás casos un cierto patrón o modelo. Así, la opción de foro es utilizada en los sistemas de solución de controversias pertenecientes a áreas de preferencias arancelarias $^{44}$, como los AAP revisados en el marco de la ALADI, y a zonas de libre comercio, es decir, en esquemas que, dudosamente, pueden ser calificados como procesos de integración ${ }^{45}$.

Por el contrario, cuando se analizan procesos de integración en sentido estricto, con objetivos más comprometidos y de mayor alcance, como un mercado común o una unión económica, los sistemas de solución de controversias acordados en ellos introducen la figura de la jurisdicción exclusiva y excluyente, tal los casos de la CAN, el CARICOM y la UE.

\section{La doctrina regional dividida}

Luego de la aprobación del PO en el 2002, la doctrina regional se expresó de modo antagónico respecto de la valoración de la opción de foro en el sistema de solución de controversias del MERCOSUR. Con el tiempo, las posiciones de morigeraron en algunos casos, pasando de un apoyo inicial a un cuestionamiento posterior.

En cuanto a las opiniones positivas -algunas de las cuales ya hemos citado en el punto 2 de este trabajo-, tenemos que, para W. Barral, la opción de foro es un instrumento que brinda al reclamante la posibilidad de acudir a aquél sistema que presente, en cada caso, la base jurídica

44 Las áreas de preferencia arancelarias se forman cuando “...dos o más territorios aduaneros se conceden entre sí una serie de ventajas aduaneras, no extensibles a terceros, debido a la suspensión internacionalmente aceptada de la cláusula de la nación más favorecida del Acuerdo general sobre Aranceles y Comercio (GATT 47). No existe compromiso para tener los mismos aranceles para las importaciones provenientes de países miembros del Área, ni para tener la misma política comercial general". Di Biase, H.N., "Introducción al derecho de la integración con especial referencia al MERCOSUR", en Durán Martínez, A. (Coordinador), El Mercosur después de Ouro Preto, en "Revista Uruguaya de Derecho Constitucional y Político", UCUDAL, Montevideo, 1995, pág. 17. Se tiene también que “... a diferencia de una zona de libre comercio, el área de preferencias no tiene por objeto liberar lo sustancial del comercio entre países miembros". Halperín, M., "Análisis de la vigencia y compatibilidad del Tratado de Montevideo de 1980 con la nueva normativa jurídico-institucional a nivel mundial y con los recientes desarrollos del proceso de integración regional en el marco de la ALADI", Secretaría General, ALADI/SEC/Estudio 87, 28 de julio de 1995, pág. 8.

$45 \mathrm{Al}$ decir de C.Pizzolo, “...la Zona de libre comercio, al no llegar a fusionar los territorios aduaneros de los Estados parte que la conforman, no logra por sí sola una verdadera integración económica entre los mismos. Por tal razón, corresponde en principio ubicar a estas zonas en el estadio de la cooperación económica". Pizzolo, C., Pensar el MERCOSUR, Ediciones Jurídicas Cuyo, Mendoza, 1998, pág 236. 
más sólida en función de sus pretensiones ${ }^{46}$. Esta opinión es compartida por M. García del Río ${ }^{47}$.

Se ha mencionado también que, al no contar el derogado Protocolo de Brasilia con una norma semejante, se favorecían las prácticas vinculadas al "fórum shopping" o al "sistema a la carta" 48 .

Otros consideraron deseable que las controversias en el MERCOSUR sean resueltas por medio de un sistema propio; sin embargo, en la actual etapa del proceso de integración, todavía existirían conflictos que pueden ser dirimidos en la OMC con mayor provecho, en razón de que algunos aspectos comerciales están regulados de manera más extensa en este organismo ${ }^{49}$.

Para S. Negro, el contexto en el que se aprobó la opción de foro (descripto en el punto 2 de este trabajo), justificó la inclusión de dicha cláusula, a fin de evitar que el evento se reiterara ${ }^{50}$.

Por su parte, L.O.Pimentel y A.Dreyzin de Klor se preguntan cuáles pueden ser las razones por las que los Estados Partes del MERCOSUR recurrirían al sistema de solución de controversias de la OMC. La respuesta es esta: "Indiscutivelmente que o prestígio de que goza a Organização Mundial do Comércio exerce uma força de atração para o seu sistema. O entendimento relativo às normas e procedimentos pelos que se rege a solução de diferenças tende a fortalecer o mecanismo de solução de conflitos da Organização, com o efeito de reduzir a arbitrariedade e evitar a adoção de medidas unilaterais em caso de não cumprimento dos compromissos comerciais. Trata-se de um procedimento bastante expeditivo fortalecido pela prática e pelos resultados que reflete o seu acionamento ... A natureza obrigatória das decisões, a brevidade dos prazos, a automaticidade das etapas no processo e o fortalecimento dos mecanismos

\footnotetext{
46 Barral, W., op.cit., pág. 276.

47 García del Río, M., op.cit., pág. 178.

48 Pagani, A., "Negociación y legalidad en la estructura institucional del MERCOSUR - El sistema de solución de controversias", en Revista de la Facultad de Ciencias Empresariales, $\mathrm{N}^{\circ}$ 3, Año 2, octubre de 2004, pág. 37. Como lo señala la Comisión Europea, "El «forum shopping» es un concepto propio del Derecho internacional privado. La persona que toma la iniciativa de una acción judicial puede verse tentada a elegir el tribunal en función de la ley que éste aplicará. La persona que inicia la acción puede verse tentada a elegir un foro no porque sea el más adecuado para conocer del litigio, sino porque las normas sobre conflictos de leyes que este tribunal utilizará llevarán a la aplicación de la ley que más le convenga". Comisión Europea, "Glosario", Red Judicial Europea en materia civil y mercantil, disponible en: ec.europa.eu/civiljustice/ glossary/glossary_es.htm, fecha de captura 14/09/2012.

49 Boldorini, M. C., op.cit., pág. 146.

50 Negro, S. C., "El MERCOSUR de Asunción a Olivos: los cambios de las dos últimas décadas", en Molina del Pozo (Director), Evolución histórica y jurídica de los procesos de integración en la Unión Europea y en el MERCOSUR, Eudeba, Bs.As., 2011, pág. 314.
} 
de supervisão e controle, contribuem à resolução dos conflitos por acordo mútuo. Sua força se manifesta no propósito de reduzir o unilateralismo nas relações comerciais internacionais e também na tendência para uma maior judicialização e automatismo. A isso se soma a importância que se reconhece aos relatórios e recomendações que geralmente se cumprem, existindo ademais, um mecanismo especifico para supervisionar dito cumprimento"s1.

Resultaría, así, casi irresistible para los Estados en general, y para los Estados Partes del MERCOSUR en particular, sustraerse de las cualidades del sistema OMC, sobre todo porque ellas, al parecer, se erigen como la contracara del sistema propuesto por el PO: prestigio, reducción de la arbitrariedad y el unilateralismo, celeridad, automaticidad, supervisión, control, fortaleza, resultados positivos, carácter vinculante de sus resoluciones, cumplimiento y vigilancia de las mismas. La opinión transcripta -de indudable valía-, sin embargo, no es compartida, como es de esperar, por la totalidad del basto mundo de los especialistas y estudiosos de los procesos desarrollados en la $\mathrm{OMC}^{52}$. De cualquier

51 "Indiscutiblemente que el prestigio de la Organización Mundial del Comercio constituye una fuerza de atracción para el sistema. El entendimiento relativo a las normas y procedimientos por los que se rige para resolver las diferencias tiende a reforzar el mecanismo de solución de conflictos de la Organización, con el efecto de reducir la arbitrariedad y evitar la adopción de medidas unilaterales en caso de incumplimiento de los compromisos comerciales. Se trata de un procedimiento bastante expedito fortalecido por la práctica y por los resultados que refleja su accionar... El carácter vinculante de las decisiones, la brevedad de sus plazos, la automaticidad de las etapas del proceso y el fortalecimiento de los mecanismos de supervisión y control, contribuyen a la solución de las controversias por acuerdo mutuo. Su fuerza se manifiesta por el propósito de reducir el unilateralismo en las relaciones comerciales internacionales, así como la tendencia hacia una mayor automatización y judicialización. A esto se suma la importancia que concede a los informes y recomendaciones que por lo general se cumplen, existiendo, además, un mecanismo específico para vigilar dicho cumplimiento". Pimentel, L.O. - Dreyzin de Klor, A., "O sistema de solução", op.cit., pág. 175 y 176.

52 Respecto de la OMC, se ha dicho que es "...otra burocracia internacional, cuyos funcionarios serán ampliamente autónomos. Informarán a 120 países $y$, por tanto, en la práctica, a nadie. ... Cada una de las naciones... entregará el control fina de sus economías a un grupo de burócratas internacionales no elegidos democráticamente y no sometidos a control alguno". Goldsmith, J., La trampa, Editorial Atlántida, Bs.As., 1996, pág. 52 y 53. Más concretamente, el sistema de solución de controversias de la OMC, con respecto a los países menos desarrollados, acarrearía un conjunto de costos para estos; a saber: i) políticos, derivados de presiones de los países más desarrollados, quienes buscarían evitar ser sometidos al sistema de solución de controversias de la OMC; ii) económicos: éstos se han incrementado, generando dificultades de acceso al sistema; además, "Los costos económicos traen implicaciones en varios aspectos como la falta de capacidad humana, institucional y técnica, y representan el principal impedimento de la participación efectiva de los PED en el OSD ..."; iii) falta de capacidad de retorsión: “...las economías muy pequeñas difícilmente podrán causar suficiente 'presión', la imposición de medidas de retorsión muchas veces acaba perjudicando a los propios países en desarrollo ganadores de la demanda, las economías ricas poseen otros mecanismos para neutralizar los efectos negativos de las medidas de retorsión aplicadas en contra de sus productos, los países desarrollados se encuentran más "fortalecidos" para someterse a medidas de retorsión teniendo en cuenta su situación económica privilegiada para hacer frente a posibles pérdidas". Salles Almeida, J., "Una década de funcionamiento del sistema de solución de diferencias comerciales de la OMC: avances y desafíos", en Serie "Comercio Internacional”, N 65, CEPAL, Santiago de 
manera, no es este el lugar adecuado para efectuar una revisión detenida del sistema de solución de controversia de este organismo internacional por lo que preferimos dejar la cuestión aquí.

Volviendo a la opción de foro del PO, tenemos que los pareceres de carácter negativo también se multiplicaron en la región. Otra vez debemos citar a L.O.Pimentel y A.Dreyzin de Klor, quienes, en una evaluación de los aspectos aceptables y cuestionables de la opción de foro, señalan que "As desvantagens de possibilitar a eleição de foro residem no debilitamento que pode ser produzido no sistema de integração; ademais pode dar lugar ao forum shopping' o que se compreenderia perfeitamente num modelo de zona de livre comércio, mas parece difícil de ser admitido num processo pelo qual se tenta avançar para um grau maior de integração com órgãos que geram normas de forma duradoura"53.

La última autora citada, admite un cambio de postura en torno a la cuestión. Si antes observaba ventajas en este dispositivo, con el tiempo, ha modificado su postura. Las razones de tal cambio son expresadas así: "La admisión del ejercicio de esta opción generó intensos debates; al analizar las innovaciones que introdujo el PO con relación al sistema de Brasilia, nos pronunciamos favorablemente a su inclusión, pudiendo sumar a los motivos esgrimidos, el hecho de que al ser el demandante el titular de este derecho, nadie mejor que él conoce si su interés legítimo queda más protegido por el PO o por el mecanismo que decida. Sin embargo, pronunciarnos favorablemente tiene un límite temporal que está dado por el Mercosur a la hora actual, en consecuencia no implica estar de acuerdo con la opción a futuro. Admitimos su inclusión atendiendo a la realidad que transita hoy el esquema, pero somos consientes que mantener esta op-

Chile, abril de 2006, pág. 50 a 54. A estas críticas se le agregan otras: "Entre el primer tipo de críticas destacan aquellas relacionadas con la integración de los grupos especiales, la transparencia, la carencia de un procedimiento de reenvio por parte del OA a los grupos especiales, la participación de los países en desarrollo, el problema de la secuencia y, en especial, diversos aspectos relacionados con los mecanismos para promover el cumplimiento de los informes. Quizás la más importante de las críticas es de carácter más general y hace referencia al desbalance que existe entre el proceso de adjudicación y el proceso político de toma de decisiones". González. A., "La solución de controversias en los acuerdos regionales de América Latina con países desarrollados", en Serie "Comercio Internacional", N 68, CEPAL, Santiago de Chile, abril de 2006, pág.19. Ver, además: Baptista, L.O., "El Área de Libre Comercio de las Américas (ALCA): un sistema de solución de controversias incierto en una era colmada de incertidumbres", en Lacarte, J. - Granados, J., Solución de controversias comerciales intergubernamentales: Enfoques multilaterales y regionales, Instituto para la Integración de América Latina y el Caribe, BID-INTAL, Bs.As., 2004, pág. 232; Condon, B.J., El derecho de la Organización Mundial de Comercio: Tratados, jurisprudencia y práctica, Cameron May, London, 2007, pág. 732.

53 "Las desventajas de posibilitar la elección de foro reside en el debilitamiento que puede producir en el sistema de integración; además puede dar lugar al 'forum shopping', el que se comprendería perfectamente en un modelo de zona de libre comercio, pero parece difícil de admitir en un proceso por el cual se tenga que avanzar hacia un grado mayor de integración con órganos que generen normas de forma duradera". Pimentel, L.O. - Dreyzin de Klor, A., "O sistema de solução", op.cit., pág. 176 y 177. 
ción es incompatible con la esencia del proceso de integración en su núcleo mismo al poner en tela de juicio la confianza que merece el sistema" ${ }^{34}$.

En el periodo inmediato posterior a la aprobación del PO, se mencionaban algunas hipótesis que introducían reparos o dudas sobre el dispositivo. Por ejemplo, se especulaba que si un Estado Parte del MERCOSUR, aún con un laudo contrario a sus intereses, emitido en el marco del PO, decidiera, no obstante, recurrir al sistema de solución de controversias de la OMC, debido a que la prohibición del art.1.2 no obliga a este organismo, el procedimiento, no obstante, seguiría su curs ${ }^{55}$.

Otra duda era expresada en estos términos: "Se, no âmbito do bloco, dois estados " $A$ " $e$ " $B$ " demandam e um resta vencido e a normativa ou a interpretação que se deu é incompatível, por exemplo, em relação ao que pensa o estado "C", poderia o estado " $C$ ", em relação ao mesmo assunto, acionar a Organização Mundial do Comércio e não acionar o sistema de solução de controvérsias nessa cláusula de opção de foro?" ${ }^{56}$.

$\mathrm{Al}$ repasar los cambios incorporados por el $\mathrm{PO}$ respecto del protocolo derogado, A.Perotti sostenía: "Se contempla el supuesto de controversias paralelas en foros internacionales (por ejemplo, en la OMC). Lo cual es un error impuesto por una práctica contraria al tratado de Asunción" ${ }^{\prime \prime}$.

Para otros, la cláusula de opción de foro conspira contra la identidad del proceso de integración del MERCOSUR, agregándose que las controversias surgidas en su ámbito no pueden tener un mejor ni más apropiado foro que el previsto en su ordenamiento jurídico. La facultad de elección que brinda el $\mathrm{PO}$ al demandante puede dar lugar a manejos y maniobras no deseables y así distorsionar los objetivos del sistema de controversias $^{58}$.

54 Dreyzin de Klor, A., "El Reglamento del Protocolo de Olivos. Algunas anotaciones", en "Revista del Foro Constitucional Iberoamericano", Madrid, $\mathrm{N}^{\circ}$ 5, Enero-Marzo, pág. 2.

55 Garcia, M., "2 Encontro de Cortes Supremas do Mercosul”, 28, 29 y 30 de 2004, Brasilia, opinión expresada en la segunda parte del día 30/11/2004, pág. 344 y 345; disponible en: www. stf.jus.br; fecha de captura: 23/09/2012.

56 "Si, dentro del bloque, dos estados, "A" $y$ " $B$ ", se demandan y uno queda vencido, y los reglamentos o la interpretación que se ha dado es incompatible, por ejemplo, en relación a lo que piensa el estado " $C$ ", ¿podría " $C$ ", con respecto al mismo tema, accionar ante la Organización Mundial del Comercio, y no accionar ante el sistema de solución de controversias, apelando a la opción de foro?”. Ídem, pág. 345.

57 Perotti, A., "Qué significó el Protocolo de Olivos", en diarios "La Nación", Sección Comercio Exterior, Bs.As., 26/02/02.

58 Puceiro Ripoll, R., "El Protocolo de Olivos: sus reformas esenciales y su significación en el régimen de solución de controversias del Mercosur", en Dreyzin de Klor, A. - Pimentel, L.O. Kegel, P.L. - Barral, W., Solução de controvérsias ..., op.cit., pág. 221. 
Finalmente, en opinión de C.Pizzolo, “...la introducción de una cláusula de opción de foro en el sistema de solución de controversias del Mercosur no fue oportuna. Ello en virtud de la situación generalizada de crisis que este proceso atraviesa y que todos los actores de la integración reconocen. Una cosa es que se trate de evitar la duplicidad de procedimientos, como de hecho venía sucediendo entre el PB y la OMC, dotando a la opción de foro un carácter excluyente; y otro muy distinto es reconocer la opción misma habilitando la salida voluntaria del sistema. Lo primero nunca debió ser tolerado ya que significó premiar el incumplimiento y la violación de la cosa juzgada propia de los laudos arbitrales emitidos por los TAH intervinientes en su momento bajo el $P B$ que no contemplaba expresamente dicha opción. Lo segundo, implica ampliar la sangría de procesos hacia otros foros ajenos al Mercosur con el consiguiente debilitamiento de éste. Quienes han intervenido en la redacción del PO probablemente fueron conscientes de este peligro y, si bien reconocieron la opción de foro, dejaron toda la cuestión abierta a la futura reglamentación que de la misma haga el CMC"59.

\section{Opción de los Estados Partes del MERCOSUR por el sistema de solución de controversias de la OMC}

En los párrafos precedentes se ha podido constatar la preocupación de diversos autores respecto del debilitamiento del sistema de solución de controversias del MERCOSUR, ante la hipótesis de que los Estados Partes recurran a la OMC; incluso, alguno de ellos deslizó la posibilidad de una "sangría" hacia otros foros. Luego de diez años de aprobado el PO, ¿se ha verificado una migración importante hacia el sistema de la OMC? Pese a los presagios antes señalados, la realidad indica que los Estados Partes del MERCOSUR recurrieron a la OMC en una sola oportunidad para dirimir controversias mutuas; además, y como se verá a continuación, el caso no llegó a sustanciarse en su totalidad.

En efecto, la Argentina concurrió en los últimos años al sistema de solución de controversias de la OMC, como reclamante, en dieciocho ca$\operatorname{sos}^{60}$; como demandada, en veintiún casos. La última demanda a este país proveniente de otro país del MERCOSUR, fue interpuesta por Brasil en el recordado caso "pollos" ${ }^{\text {"1 }}$, previo, como se sabe, a la aprobación del PO.

59 Pizzolo, C., Derecho e integración..., op.cit., pág. 1062.

60 Los datos referidos a las controversias que involucraron a Estados Partes del MERCOSUR, fueron consultados en: www.wto.org/spanish/tratop_s/dispu_s/cases_s/ds241_s.htm; fecha de captura: 05/10, 2012. (datos validos al 24/10/2012).

61 Ver: nota al pie $\mathrm{N}^{\circ} 9$ de este mismo trabajo. La solicitud de celebración de consultas fue presentada por Brasil el 12/11/2001; Consultar: OMC, WT/DS241/1 - G/L/505 - G/ADP/D38/1 - G/VAL/D/6, del 12 de noviembre de 2001. 
Brasil, por su parte, actuó como reclamante en veintiséis casos; como demandado, en catorce oportunidades. La última demanda interpuesta a Brasil por un Estado Parte del MERCOSUR -la Argentina- fue presentada ante la OMC el 26 de diciembre de 2006, en el caso conocido como "resinas" 62 . Se trata, entonces, de un caso de opción de foro, en la medida en que se ha constituido el Grupo Especial en los términos del art. 6 del "Entendimiento relativo a las normas y procedimientos por los que se rige la solución de diferencias" ${ }^{63}$, de la OMC; según el reglamento del PO citado más arriba, la opción por el sistema de solución de controversias de la OMC queda efectuada con el pedido de establecimiento del mencionado grupo.

Como se sabe, en 2008, la Cámara de Comercio Exterior del Brasil suspendió la aplicación de derechos antidumping a las importaciones de resina procedentes de la Argentina. Como consecuencia de ello, la Argentina solicitó al Grupo Especial que suspendiera sus trabajos. Con relación a este trámite, en la página web de la OMC se lee: "Al no haberse pedido al Grupo Especial que reanude sus trabajos, la decisión de establecerlo, en virtud de lo dispuesto en el párrafo 12 del artículo $12 \mathrm{del}$ ESD, quedó sin efecto el 5 de febrero de 2009".

A su vez, Uruguay se constituyó en parte reclamante en una ocasión, y como demandada también en una sola controversia; en ninguna de ellas se vio involucrado otro Estado Parte del MERCOSUR.

Venezuela efectuó un solo reclamo, y fue demandada en dos oportunidades. Ningún otro Estado Partes del MERCOSUR estuvo involucrado en el procedimiento como parte.

Al momento, Paraguay nunca fue parte en el sistema de solución de controversias de la OMC.

Se puede apreciar que tanto Brasil como Argentina han utilizado de manera profusa el sistema de la OMC, tanto como reclamantes como demandados. Sin embargo, los datos aquí consignados, por sí solos, demuestran que, hasta la fecha, los Estado Partes del MERCOSUR han preferido dirimir sus controversias en la región, evitando recurrir -salvo el caso apuntado- a otro foro distinto del MERCOSUR. ¿Se deduce de

62 OMC, Grupo Especial, "Brasil - Medidas antidumping sobre las importaciones de determinadas resinas procedentes de la Argentina”, Diferencia DS355, Solicitud de celebración de consultas presentada por la Argentina, WT/DS355/1G/L/810G/ADP/D71/1, 9 de enero de 2007.

63 OMC, Acuerdo por el que se establece la Organización Mundial del Comercio - Anexo 2, "Entendimiento relativo a las normas y procedimientos por los que se rige la solución de diferencias", consultado en: www.wto.org; fecha de captura: 23/05/2012. 
ello, sin más, la fortaleza del PO y la intrascendencia de la opción de foro como un factor de debilidad del sistema?

Veamos.

\section{Incompatibilidad de la opción de foro con los objetivos del MERCOSUR}

¿Cuáles son los criterios adecuados para evaluar la cláusula de opción de foro aquí analizada? Esta pregunta podría, sin dificultad, estar precedida de otra, más comprensiva: ¿cuáles son los criterios adecuados para evaluar las normas del PO?

El conocimiento jurídico otorga, con seguridad, un importante bagaje de respuestas a estas cuestiones. No es posible, como se comprenderá, abordar todas ellas en esta breve exposición, por lo que preferimos no apartarnos del ámbito de la solución de controversias del MERCOSUR. Por ello, tomamos en consideración el Primer Laudo Arbitral, del año 1998, calificado en su momento como inteligente y oportuno ${ }^{64}$. En él se adopta expresamente el método teleológico en la interpretación del plexo jurídico mercosurino. En base a esta perspectiva, todo dispositivo jurídico del MERCOSUR debe ser analizado como medio o instrumento puesto en vigencia para alcanzar aquella finalidad expresamente determinada en el Tratado de Asunción -la constitución final del mercado común- ${ }^{65}$, reafirmada en el Protocolo de Ouro Preto ${ }^{66}$-ambas máximas instancias del ordenamiento jurídico regional- y reiterada por otras normas de menor jerarquía ${ }^{67}$.

64 Peña, F. “Un fallo inteligente y oportuno", Diario "La Nación”, Bs.As., del 25/05/1999.

$65 \mathrm{El}$ art. 1 del tratado de Asunción dice: "Los Estados Partes deciden constituir un Mercado Común, que deberá estar conformado al 31 de diciembre de 1994, el que se denominará "Mercado Común del Sur" (MERCOSUR)".

66 En los considerandos del Protocolo de Ouro Preto se lee: "Conscientes de la importancia de los avances alcanzados y de la puesta en funcionamiento de la unión aduanera como etapa para la construcción del mercado común; Reafirmando los principios y objetivos del Tratado de Asunción...".

67 En los Considerandos de la Decisión del Consejo del Mercado Común, del año 2006, relativa a la "Evolución de la integración comunitaria", MERCOSUR/CMC/DEC. No 22/06, se afirma: "Que la profundización del MERCOSUR debe centrarse en el cumplimiento de las metas trazadas en el Tratado de Asunción, y que al efecto se precisa fortalecer las instituciones fundamentales que inspiraron su constitución". El mismo órgano del MERCOSUR, al dictar la Decisión MERCOSUR/CMC/DEC. No 29/06, en su segundo Considerando reitera casi textualmente lo ya sostenido en el instrumento precitado, señalando: "Que el proceso de profundización del MERCOSUR debe centrarse en el efectivo cumplimiento de las metas establecidas en el Tratado de Asunción, para lo cual es necesario fortalecer las instituciones fundamentales que inspiraron su constitución". Aunque también debe señalarse que referencias expresas al mercado común han desaparecido casi completamente en los instrumentos oficiales del MERCOSUR. Según pudo constar el autor de esta ponencia, el último comunicado conjunto de los Presidentes del MERCOSUR donde se hace mención al mercado común data del 5 de agosto de 1994. En el numeral 7 de este comunicado se lee: "Los Presidentes destacaron los 
Se procura, de esta manera, “...garantizar que las normas 'sean eficaces en relación con su fin último, que es el de dar satisfacción a las exigencias de la integración'... Los fines y objetivos no son un adorno de los instrumentos de integración sino una guía concreta para la interpretación y para la acción... la interpretación de las disposiciones en un conjunto normativo cuyo fin es la integración debe guiarse por este propósito y hacerlo posible"68.

Surge así otra pregunta de carácter fundamental: ¿contribuye la cláusula de opción de foro, en tanto instrumento jurídico-normativo, a la constitución final del mercado común o al perfeccionamiento de la unión aduanera, esta última como objetivo intermedio? Queda claro a estas alturas que el objetivo originalmente señalado en el Tratado de Asunción no se ha conseguido en el término estipulado, por las razones que son harto conocidas y que no viene a cuento señalarlas aquí. Es así que la actualidad del MERCOSUR se debate en torno a la concreción de una unión aduanera con características de "imperfecta", según lo explicita la doctrina especializada ${ }^{69}$. De cualquier manera, el mercado común sigue siendo el objetivo final del MERCOSUR. Aunque ya sin fecha cierta, tal meta continúa iluminando el camino que ha de recorrer este proceso de integración, por lo que, entendemos, cada dispositivo jurídico puesto en vigencia en su seno se debe acomodarse a la misma, sin perder de vista la necesaria flexibilidad que demanda la etapa por la se transita al momento.

En este sentido, un objetivo de tanta trascendencia no puede ser concretado con instrumentos propios de una zona de libre comercio. El mercado común requiere, necesariamente, de un conjunto de soluciones de carácter técnico-jurídico que consolide los esfuerzos llevados a cabo en el campo económico y comercial. Parece evidente que la posibilidad de "fuga" hacia otros foros no contribuye en gran medida en esta tarea. Por el contrario, entendemos que la jurisdicción exclusiva y excluyente se acomodaría mejor con un esquema que aspira a un mercado común, según se ha podido observar en la experiencia comparada.

importantes avances logrados para alcanzar la puesta en funcionamiento de la unión aduanera y sentar así las bases de la conformación del mercado común, reafirmando los principios y objetivos del Tratado de Asunción". Texto consultado en: www.mercosur.int.; fecha de captura: 23/05/2012.

68 Tribunal Arbitral del MERCOSUR, Laudo del Tribunal Arbitral Ad-Hoc del Mercosur constituido para entender en la Controversia de la República Argentina a la República Federativa de Brasil sobre "Comunicados No 37 del 17 de diciembre de 1997 y No 7 del 20 de febrero de 1998 del Departamento de Operaciones de Comercio Exterior (DECEX) de la Secretaría de Comercio Exterior (SECEX): Aplicación de Medidas Restrictivas al Comercio Recíproco", del 28 de abril de 1999, numeral 57 y 58.

69 Bergamaschine, Mata Diz, J., Mercosur: origen, fundamentos, normas y perspectivas, Jurua, Curitiba, 2007, pág. 36 y 37. 
Bajo esta perspectiva, la opción de foro, aún con una escasa utilización, carente por ello de efectos negativos directos, no obstante, termina afectando, con su sola existencia, la credibilidad de las instituciones del MERCOSUR, en un aspecto tan sensible como la solución de controversias. Que los Estados Partes, aún en hipótesis, quieran dirimir sus diferencias fuera del ámbito natural en el que están estrechamente relacionados, socava la confianza en cuanto a la seriedad del proceso de integración regional. Esta cláusula se erige como un elemento simbólico de carácter negativo, que envía señales equívocas a los operadores internos y externos de la región ${ }^{70}$.

El sistema de solución de controversias del MERCOSUR irá incrementando su prestigio cuando pueda hilvanar un conjunto coherente de decisiones, que sienten las bases de un sólido edificio jurisprudencial, no sólo destinado a la resolución de conflictos sino destinado a la elaboración de principios que contribuyan a apuntalar la integración regional $^{71}$. Algunas de estas ideas, al parecer, motivaron a los redactores del PO al dotarle al tribunal el carácter de "permanente"72. Tal como lo advierte S. Czar de Zalduendo, "El problema de la uniformidad en la interpretación del derecho es una cuestión que enfrenta todo sistema jurídico y que está vinculada a la consistencia del ordenamiento legal y a las situaciones que se plantean cuando hay interpretaciones divergentes. En consecuencia, las inquietudes que genera el hecho de que un mismo texto legal pueda ser objeto de elucidaciones distintas, se presentan tanto dentro de una misma jurisdicción como entre varias circunscripciones indepen-

70 En relación con lo aquí afirmado, se ha dicho que “...el método más adecuado para brindar seguridad jurídica a los Estados partes y a los operadores de la zona o extrazona que actúen en el mercado regional es el método judicial”. Moya Domínguez, M.T., Derecho de la integración, Ediar, Bs.As., 2006, pág. 417,

71 La experiencia europea muestra el servicio que un tribunal dotado de amplias facultades le puede brindar a la integración regional. Con relación al TJCE, se ha dicho que "...no es un simple órgano judicial [...] sino que se presenta como un auténtico poder judicial comunitario”. Isaac, G., Manual de derecho comunitario general, Ariel, Barcelona, 1997, pág. 263. Aún más, "A lo largo de la historia de las comunidades, el tribunal de Justicia ha contribuido decisivamente a la actual conformación del Derecho comunitario y es opinión unánime en la doctrina el reconocimiento del papel decisivo que ha jugado en la construcción de Europa". Molina del Pozo, C.F., Manual de derecho de la Comunidad Europea, Trivium, Madrid, 1997, pág. 270.

72 Se ha señalado que "Aparentemente, este mecanismo creado basado en la constitución de un tribunal que se le llama permanente de revisión, es lograr una uniformidad de interpretación de la normativa MERCOSUR. No obstante, si tomamos en cuenta que hasta ahora los nueve fallos o laudos arbitrales han recaído en conflictos entre dos Estados, todo hace suponer que en el futuro la mayoría de los conflictos serán resueltos, en caso de que se acuda al tribunal de revisión, por estos tribunales reducidos de tres miembros. Ahora bien, aunque sea una hipótesis que puede ser desvirtuada, la constitución de sucesivos tribunales de tres árbitros, aún dentro de un tribunal de cinco miembros, no puede conducir a interpretaciones también contradictorias porque no siempre van a intervenir los mismos árbitros? Lo señalo como una posibilidad que se abre". Rey Caro, E.J., "El Protocolo de Olivos para la Solución de las Controversias en el MERCOSUR", en VIII Seminario Jurídico: "La dimensión jurídica de la integración", 2 y 3 de octubre de 2003, pág. 82; disponible en: www.aladi.org; fecha de captura: 23/10/2012. 
dientes"73. .

Con todo, la prohibición que emerge de la opción de foro, no deja al ordenamiento del MERCOSUR a salvo de interpretaciones contradictorias ni de los peligros del "fórum shopping". A modo de ejemplo, señalamos que nada impide que un Estado Parte del MERCOSUR pueda recurrir al sistema de la OMC, presentando allí un caso análogo a otro previamente resuelto en el ámbito del $\mathrm{PO}$ y que no lo haya tenido como parte. En esta línea de razonamiento, ninguna norma del PO podría evitar que dos Estados Partes, "A" y "B", en relación a un mismo tema controvertido con "C", planten sus demandadas, uno ante la OMC y el otro ante el PO. Y si de agregar hipótesis de trata, tampoco podría evitarse que "A", "B" y "C" planteen sus controversias contra "D", en relación a un tema idéntico, ante tres foros distintos. Es fácil seguir imaginado otras combinaciones posibles de demandantes, en forma individual o colectiva, llevando los conflictos del MERCOSUR a cuanto foro esté habilitado, obteniéndose un conjunto de decisiones que pueden arribar a distintas soluciones.

Entonces, la posibilidad de decisiones encontradas sigue latente, pese a la opción de foro. Y si además se tiene presente que el sistema de la OMC no se encuentra obligado a resolver sus controversias conforme a la normativa ni los principios de MERCOSUR o cualquier otro proceso de integración o Estado miembro. En opinión de A.Dreyzin de Klor, "En caso de que los miembros de un esquema de integración (vgcia. Mercosur) decidan llevar la disputa a la OMC en vez de resolverla de acuerdo al sistema de solución de controversias del esquema, el Grupo Especial y el órgano de Apelación sólo se pronunciarán sobra la legalidad o no de una medida respecto a las disciplinas multilaterales ("acuerdos abarcados") y no sobre la legalidad o no de la misma respecto a las disciplinas vigentes en el propio sistema de integración" 74 .

No se consigue ninguno de los objetivos arriba apuntados fomentando el acceso de los Estados Partes a una eventual multiplicidad de foros que nada tienen que ver con las particularidades de un proceso como el MERCOSUR. Por caso, los objetivos de la OMC -junto con su peculiar naturaleza- ${ }^{75}$, y por más prestigio que pueda exhibir su sistema

73 Czar de Zalduendo, S., "El Protocolo de Olivos y la interpretación uniforme de la normativa MERCOSUR", en Solução de Controvérsias no Mercosul, op.cit., pág. 243.

74 Dreyzin de Klor, A., "El Protocolo de Olivos", en "Revista del Derecho Privado y Comunitario", Rubinzal-Culzoni, 2003, Nº 1, pág. 588.

75 Es importante tener presente que en las negociaciones de la OMC, se aplica el principio "quid pro quo", casi coincidente con el principio de "reciprocidad". respecto del viejo GATT, ya se decía que "Su finalidad está en la reducción de las tarifas aduaneras y en estimular los intereses comerciales sobre la base de la reciprocidad". Fuentes Pérez, P., Las instituciones supranacionales, AKAL, Madrid, 1989, pág.15. Estos principios no resultan para nada adecuados en el 
de solución de diferencias, distan largamente de aquellos que son procurados en nuestra región, por lo que sus decisiones poco aportarán al avance o profundización del MERCOSUR.

\section{Algunas reflexiones}

Pese a la desafortunada inclusión de la opción de foro en el sistema de solución de controversias del MERCOSUR, de todas maneras, quizás este instrumento no sea el defecto más notorio del PO. Resulta, hasta si se quiere, imperceptible, al menos si se lo compara con otros defectos e inconsecuencias de la integración regional. Si bien el Tribunal Permanente de Revisión ha significado un avance respecto del sistema puramente arbitral contenido en el Protocolo de Brasilia, aún dista en demasía de un sistema destinado a coadyuvar en la construcción del mercado común, o al menos apuntalar las bases de una unión aduanera.

Es por ello que acompañamos las múltiples opiniones de la doctrina regional, la que brega por un Tribunal permanente, con características jurisdiccionales, dotado de mayores atribuciones y capacidades, en condiciones de acompañar de modo más efectivo a la integración regional $^{76}$. En un esquema jurisdiccional de tales características, la opción de foro sería un elemento extraño, sin un sentido práctico, sin provecho alguno.

De todas formas, la opción de foro no resulta más que una metáfora del estado actual del MERCOSUR, con marcadas inconsecuencias y contradicciones, no sólo en cuanto a su sistema de solución de controversias.

marco de un proyecto con los objetivos declarados por el MERCOSUR. Como dice C.Pizzolo, "De los dos tipos de integración que conocemos, la fórmula de la reciprocidad es propia de tipo de cooperación y asociación regida por el derecho internacional, donde no ha operado transferencia de ninguno de los atributos de soberanía y las relaciones se guían por la confianza más que por cualquier otra cosa. En la integración de tipo comunitaria, por el contrario, la fórmula de reciprocidad pierde relevancia pues el derecho comunitario que nace de ella es un derecho autónomo que se beneficia de las atribuciones de soberanas cedidas por los Estados miembros". Pizzolo, C., Pensar ..., op.cit., pág. 175 y 176.

76 En un excelente trabajo realizado por el Dr. R. Ruiz Díaz Labrano, se lee, entre otras cosas, lo que sigue: "La reforma del Sistema de Solución de Controversias del MERCOSUR podría producirse dotando al Tribunal Permanente de Revisión de competencias que pudieran ser ejercidas más ágilmente y con mayor independencia funcional [...] un Tribunal del MERCOSUR, con competencias y atribuciones más cercanas a un órgano jurisdiccional [...] un órgano de justicia con mayores competencias, si en verdad se apunta a consolidar una Unión Aduanera como paso previo a establecer un Mercado Común [...] Lo mismo cabe decir del examen y modificación de la reglamentación, debería estar direccionada a una mayor independencia del tribunal permanente de Revisión respecto de los demás órganos, a fin de encaminar al órgano hacia un sistema jurisdiccional comunitario, acompañando la evolución y los objetivos trazados en el MERCOSUR". Ruiz Díaz Labrano, R., "Evolución institucional del MERCOSUR. Un tribunal permanente arbitral o jurisdiccional para el MERCOSUR”, en Molina del Pozo, op.cit., pág. 354, 355, 357 y 360. 
Los verdaderos inconvenientes de la integración regional se ubican en otro plano.

El discurso en pro de la integración Latinoamericana se cuela en todos los ambientes políticos de esta hora. Sin embargo, el problema de la integración regional no son los discursos, sino las prácticas. Entendemos que el discurso político no logra sortear la barrera de las buenas intenciones para devenir en operatividad, en cambio concreto, en acción transformadora de la realidad.

Podría argumentarse que el actual contexto internacional reclama prudencia, lo que obliga a los Estados a refugiarse en sus políticas internas. Un razonamiento semejante no resulta descabellado; pero entendemos que la crisis consignada puede servir como una excelente excusa para profundizar los mecanismos "defensivos" que brindan los procesos de integración regional, obteniéndose soluciones comunitarias antes que individuales.

De ser así, la integración regional reclama la puesta en acto de un conjunto de técnicas que le den forma a los designios políticos.

En consecuencia, se necesita, entre otras cosas, más allá de las buenas intenciones. Se precisa de una estructura institucional dotada de poderes reales para llevar a cabo su cometido. Un órgano jurisdiccional permanente, dotado de competencias exclusivas, podría ser un buen inicio.

Es imprescindible introducir modificaciones en el sistema de toma de decisiones ${ }^{77}$.

Se necesita del desarrollo y expansión de disciplinas técnicas, económicas, comerciales y jurídicas que apunte a la construcción del mercado común. No es una buena señal la generalización de las perforaciones al arancel externo común, lo que hiere de muerte a la unión aduanera.

77 Como se ha dicho, "La realidad de los hechos muestra que sólo un escaso porcentaje de las normas emanadas de los órganos del Mercosur son incorporadas a los ordenamientos jurídicos de los Estados Parte. Los mecanismos existentes a esos efectos operan en general de manera lenta y a veces enfrentan barreras difíciles de salvar". Fresnedo de Aguirre, C., "Un importante avance en la democratización del proceso decisorio en el MERCOSUR: el acuerdo interinstitucional Consejo Mercado Común - Comisión Parlamentaria Conjunta", en: www.opalc.org/, fecha de captura, 22/10/2012. En algunos documentos se habla de un porcentaje de incorporación del 30\%. Ver: Seminario "Las normas de derecho originario y derivado del MERCOSUR. Su incorporación a los ordenamientos jurídicos de los Estados Partes". Secretaría Administrativa del MERCOSUR (SAM), Montevideo, República Oriental del Uruguay, 26 y 27 de septiembre de 2002, pág. 6 y 7; en: www.cari.org.ar, fecha de captura: 22/10/2012. 
Se requiere de una burocracia (en el buen sentido) especializada y bajo el tutelaje de la política, para llevar a cabo la "letra chica" de la integración.

Se necesita de recursos concretos -y en mayor volumen- aportado por quienes más tienen, en una suerte de redistribución de la riqueza a escala regional.

Es necesario un reexamen de las políticas impulsadas con Paraguay. En sus últimas sesiones, el Senado de ese país aplazó indefinidamente el ingreso a la UNASUR del país guaraní. Este no es un dato positivo, teniendo en cuenta su anterior rechazo al ingreso de Venezuela como miembro pleno del MERCOSUR.

Se necesita, al menos, no retroceder en lo ya andado.

En el caso del MERCOSUR, si este habrá de mantener el objetivo de constituir un mercado común o al menos una unión aduanera, sus integrantes no tendrán más remedio que desprenderse de algunas atribuciones, y entregarlas a algún organismo regional. Sin normas de aplicabilidad inmediata y efecto directo, y sin órganos autónomos e independientes, el MERCOSUR deberá sincerarse y pensar en otras finalidades, más modestas, como una zona de libre comercio, aun cuando este esquema no pueda considerarse "técnicamente" como una parte integración económica, como se dijo más arriba. O bien "congelar" el proceso, como sugieren algunos ${ }^{78}$. Lo que no puede hacer es seguir manteniendo las ya antiguas expectativas y no actuar en consecuencia.

Como afirma R.Ruiz Díaz Labrano, “...no hay manera de constituir el mercado común sin alguna forma atenuada de supranacionalidad; en las presentes circunstancias, se podrá llegar a una unión aduanera, pero no más allá"79.

78 “..existe una solución alternativa a las planteadas que al menos restablece la credibilidad, rentabiliza los recursos humanos y materiales dedicados a la gestión del MERCOSUR y, lo que es más importante, frena radicalmente el agravamiento de la actual situación. Se trata de decidir de manera explícita, transparente y honesta hibernar al MERCOSUR en tanto que proceso de integración a la espera de tiempos mejores. No se trata de destruir el acervo (el acquis) del MERCOSUR en la medida en que éste existe. Se trata más bien de 'congelarlo', de dejar de hablar de su relanzamiento y aceptar modestamente que, al menos de omento, no se puede ir más allá... Mejor es, pues, congelar el proceso mientras aún queda dentro de él algún dinamismo y esperanza de revitalización". Torrent, R., "Una aproximación a la anatomía del MERCOSUR real", en Berlinski, J. - Pires de Souza, F.E. - Chudnovsky, D. - López, A., (Coordinadores), 15 años de MERCOSUR: comercio, macroeconomía e inversiones extranjeras, Red de Investigaciones económicas del MERCOSUR, Montevideo, 2006, pág. 71 y 72.

79 Expresiones del Dr.R.Ruiz Diaz Labrano, emitidas en el marco del XIII Cursos Intensivos de Posgrado, "Estado, integración regional y políticas públicas", Facultad de Derecho de la UBA, Bs.As, clase del 11/07/2012. 
En la actualidad se habla mucho de la revolución bolivariana; se habla, así, de Bolívar, de San Martín, a lose podría agregar sin dificultad al Mariscal López, a Getulio Vargas, a José Artigas, a O’Higgins, a Perón. Todos ellos defensores de una Latinoamérica unida y solidaria. Eran todos hombres de acción. Eran revolucionarios, que combinaban los altos ideales que los movilizaban sus grandes gestas, con las necesidades impuestas por la realidad.

El MERCOSUR de hoy tiene que recuperar ese espíritu, dando paso a una revolución, pacífica y con armas políticas y jurídicas, que combine en su justa medida, el idealismo de la unidad latinoamericana con la realidad de la política y los intereses de coyuntura. Tal revolución, en gran medida, debe darse en el plano jurídico-institucional.

Adaptando el viejo dicho, decimos que: "El MERCOSUR será revolucionario o no será nada”. 